\title{
EAl Endorsed Transactions

\section{Diagnosis of Arthritis Using Adaptive Hierarchical Mamdani Fuzzy Type-1 Expert System}

\author{
Shahan Yamin Siddiqui ${ }^{1,2,}$, Syed Anwar Hussnain ${ }^{1}$, Abdul Hannan Siddiqui ${ }^{3}$, Rimsha Ghufran ${ }^{4}$, \\ Muhammad Saleem Khan ${ }^{1}$, Muhammad Sohail Irshad ${ }^{2}$, Abdul Hannan Khan ${ }^{2}$
}

\author{
${ }^{1}$ School of Computer Science, National College of Business Administration \& Economics, Lahore, Pakistan \\ ${ }^{2}$ Department of Computer Science, Minhaj University, Lahore, Pakistan \\ ${ }^{3}$ Cavan General Hospital Lisdaran, Cavan, Ireland \\ ${ }^{4}$ Allied Hospital Faisalabad, Pakistan
}

\section{Abstract}

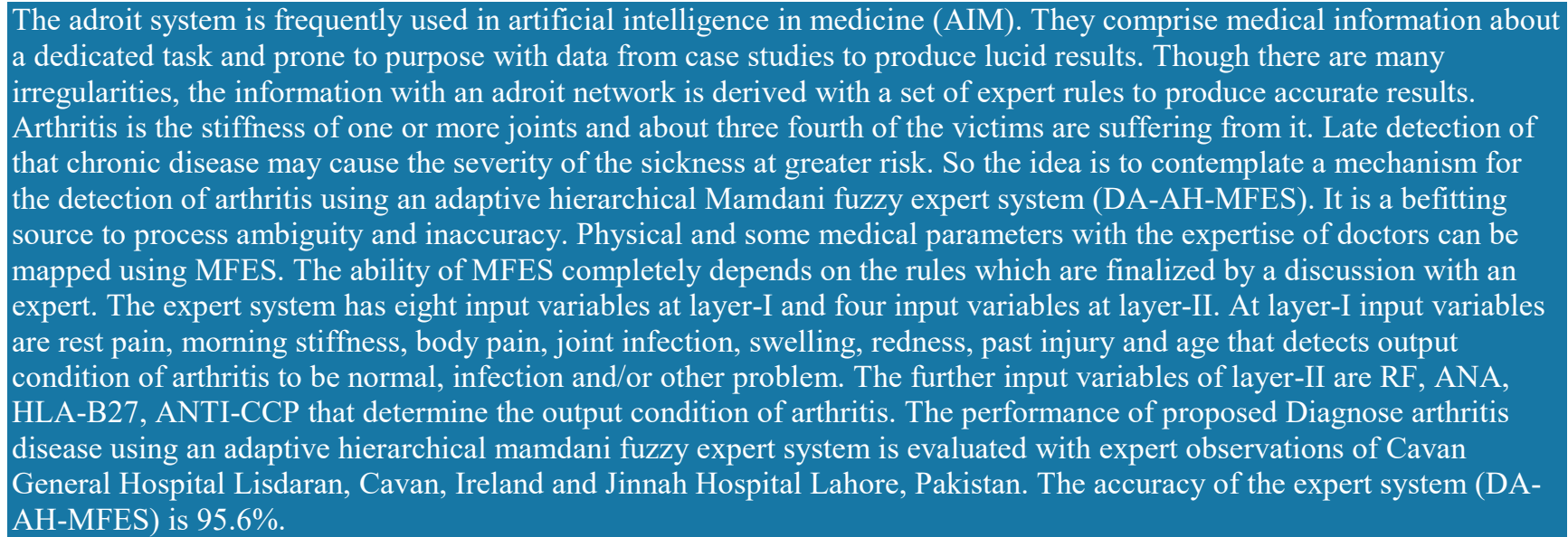

Keywords: Arthritis, Osteoarthritis, Rheumatoid arthritis, DA, MFES, DA-AH, MFES

Received on 27 September 2019, accepted on 01 November 2019, published on 18 November 2019

Copyright $(C 2019$ Shahan Yamin Siddiqui et al., licensed to EAI. This is an open access article distributed under the terms of the Creative Commons Attribution licence (http://creativecommons.org/licenses/by/3.0/), which permits unlimited use, distribution and reproduction in any medium so long as the original work is properly cited.

doi: 10.4108/eai.13-7-2018.161439

*Corresponding author. Email: engr.shahansiddiqui@gmail.com

\section{Introduction}

Arthritis is the stiffness of one or more than one of your joints. Normally it is considered that if it influences old people but it can attack any age person. It is a chronic disease and a term that includes a group of disorders that affect joints and muscles [1]. Arthritis is a lifelong disorder and approximately three fourth of the sufferers are tormented by it; if it remains undiagnosed it may also cause the severances of the disorder $[2,3]$. There are two major infections of arthritis; the first one is osteoarthritis when osteoarthritis infection attacks the person's joints cartilage becomes indentation on the surface, difficult and brittle. The bone below the cartilage get thickens and also broadens out, the amount of lubrication liquid of joints decreases. In a few instances, bony outgrowths may additionally shape at the outer edges of the joint, making 
the joint seem tender. Due to osteoarthritis infection sufferer feels severe pain during movement [4].

The second type of arthritis infection is rheumatoid, in this infection membrane of joints swollen. Common symptoms of that infection feel by sufferer are stiffness, body temperature and redness. So to live a happy and healthy life it is very important to diagnose and cure that infection on time. If it remains undiagnosed in sufferer or late-diagnosed it may cause many other problems for sufferer [5]. Different expert systems are used in artificial intelligence in medical field to diagnose and cure different diseases. In this paper fuzzy logic controller is used to design an arthritis disease diagnose system. It is a very good tool that deals with uncertainty and imprecision. It is widely used in artificial intelligence to diagnose different diseases with high accuracy $[6,7,8]$.

In this article proposed a fuzzy based intelligent system that will be able to diagnose arthritis at its early stage. The proposed system contains two layers to detect and ensure sufferer disease. Few physical parameters are used at layer-I to know about the type of infection sufferer has, if layer-I confirms that sufferer has arthritis infection then layer-II become an active layer. On layer-II few medical parameters will be used to diagnose the type of arthritis infection and also the stage of that infection. The aboveexplained process to diagnose arthritis is performed with the recommendation of medical experts in any sufferer.

\section{Literature Review}

Arthritis is an ailment, Phrase 'arthritis' precisely way tenderness of the joints. The perceived and the existent studies prove that arthritis isn't always a diagnosis in itself. It is a widespread term that mentors us that something is incorrect $[9,10]$. The recent researches have used the fuzzy inference system model to diagnosis arthritis based on some physical symptoms and medical tests. The most promising controller known as fuzzy logic that determines membership functions with decides rules about diagnosis results. The designed controller diagnosed arthritis in a single layer by combining different physical and medical parameters. Parameters involved and employed showed a different level of accuracy. The proposed model of that team used physical parameters like body pain and redness and medical parameters rheumatoid Factor (RF) and anticyclic citrullinated peptide antibody (ANTI-CCP). It shows accuracy between $8 \%-82 \%[11,12,13]$.

Different causes which are considered baseline for arthritis disease. Worldwide research of his team observed fifty confirmed patients of rheumatoid arthritis having age twenty to sixty to know about common symptoms for future sufferers. They ensured in work that a common symptom that was present in sufferers and not in healthy subjects was the automated nervous system. Due to the presence of that symptoms sufferer does not feel well and does not communicate with others which leads to a short communication problem in the sufferer $[14,15]$. Although there are other infections of arthritis that exists but most
Common type of arthritis that is rheumatoid arthritis, prolonging the type Rheumatoid Arthritis, when and how it attacks the person, along with causes based on genetic symptoms, along with the symptoms, the medical remedies are also been discussed in the limelight of the arthritis [16].

Taking into account the vivid types of arthritis, osteoarthritis ailment, wear and tear infection leads to damage of cartilage and slowly cartilage damage fully and the person unable to move and work properly. The type osteoarthritis is considered to be very complex and it is a totally cartilage driven problem so it is very important to diagnose it immediately and cure it on time [17]. To analyze the origin of Rheumatoid Arthritis Smolen utilized dataset from different areas and discussed with arthritics experts. Treat to target (T2T) is used by experts of the Smolen team to cure Rheumatoid Arthritis [18]. The comprehensive discussion leads to the relation between depression and chronic rheumatoid arthritis. They utilized more than a hundred patient dataset including $77 \%$ males and $23 \%$ females. The result of the study of those patients reveals that more than $40 \%$ of the patient including both genders has some degree of depression present in their minds. The suggestions necessitate that it's miles important for treating Rheumatoid Arthritis victims to screen them for melancholy and manipulate it respectively [19]. The most alarming ailments have made the researches to approach the basic plain-film diagnosis and differential diagnosis of the arthritides and analysis of which part of the joint is involved, and works through a logical sequence to reach a final ailment [20].

A different kind of methodology has provided medical researches with a different guideline to diagnose and reduce rheumatoid arthritis. The two targeted types of sufferers have been implicate in paper and recommended different medications as per the severity of an ailment. The study of that paper reveals that although we cannot recommend it to all patients it may help us in more than half cases to reduce the infection of rheumatoid arthritis [21].

Computational Intelligence approaches like Fuzzy system [22,23], Neural Network [24], Swarm Intelligence [25] \& Evolutionary Computing [26] like Genetic Algorithm [27, 28], DE, Island GA [29], Island DE $[29,30]$ are strong candidate solution in the field of smart city $[31,32]$ and smart health $[34,35,36,37]$ etc.

\section{Related Work Fuzzy Based System Model}

Our proposed Diagnosis of Arthritis Using Adaptive Hierarchical Mamdani Fuzzy Expert System (DA-AHMFES) is described in this area. Figure 1 determines the evolution of the proposed DA-AH-MFES hierarchical approach. The DA-AH-MFES based expert System includes two layers as appeared in figure 2. In layer-I examine the Arthritis (Negative/Positive) using eight input 
variables age, morning-stiffness, body-pain, jointinfection, rest-pain, redness, swelling, past-injury and in layer-2 examine the arthritis (no/acute arthritis/chronic arthritis) using four input variables RF, ANA, HLA-B27, Anti-CCP as performed in figure 3 and figure 4 using MATLAB R2019a tool [33].

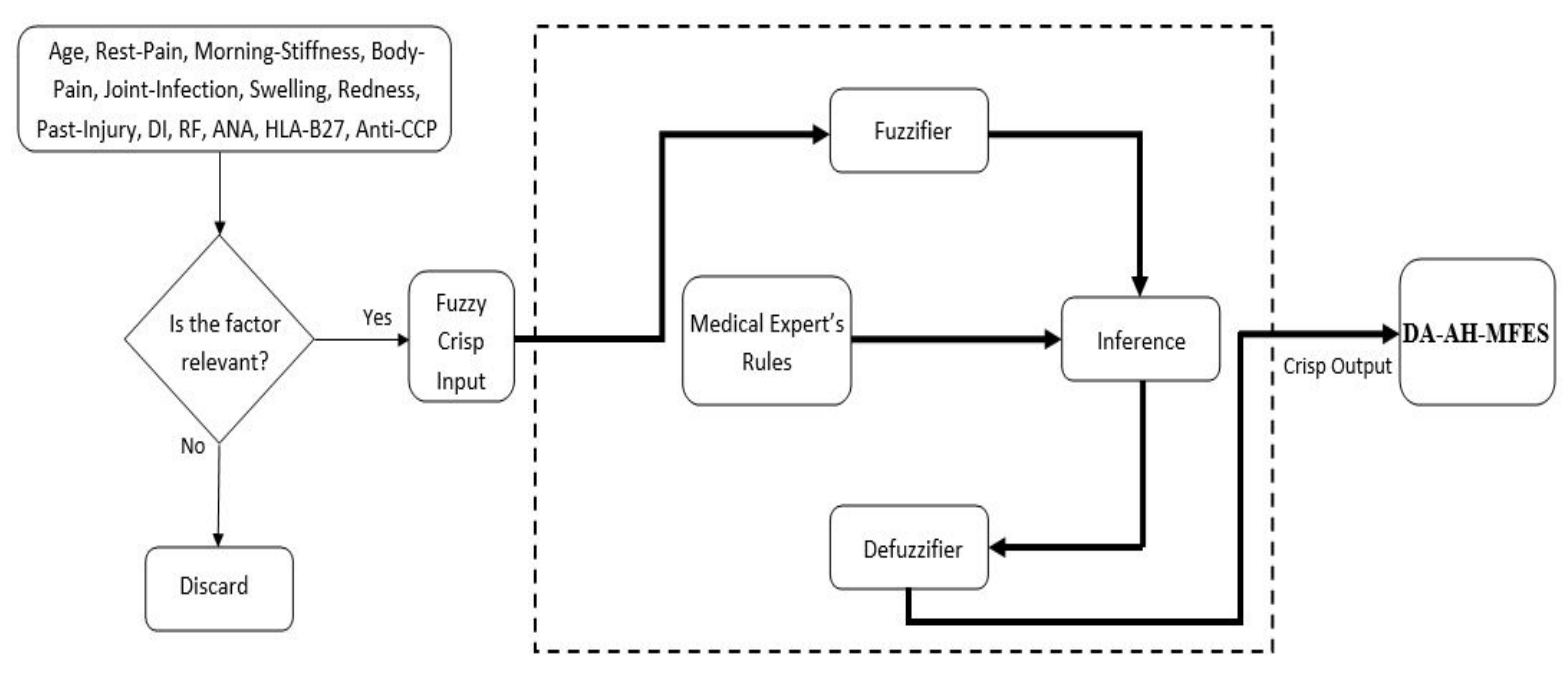

Figure 1. Proposed DA-AH-MFES based Expert System Methodology

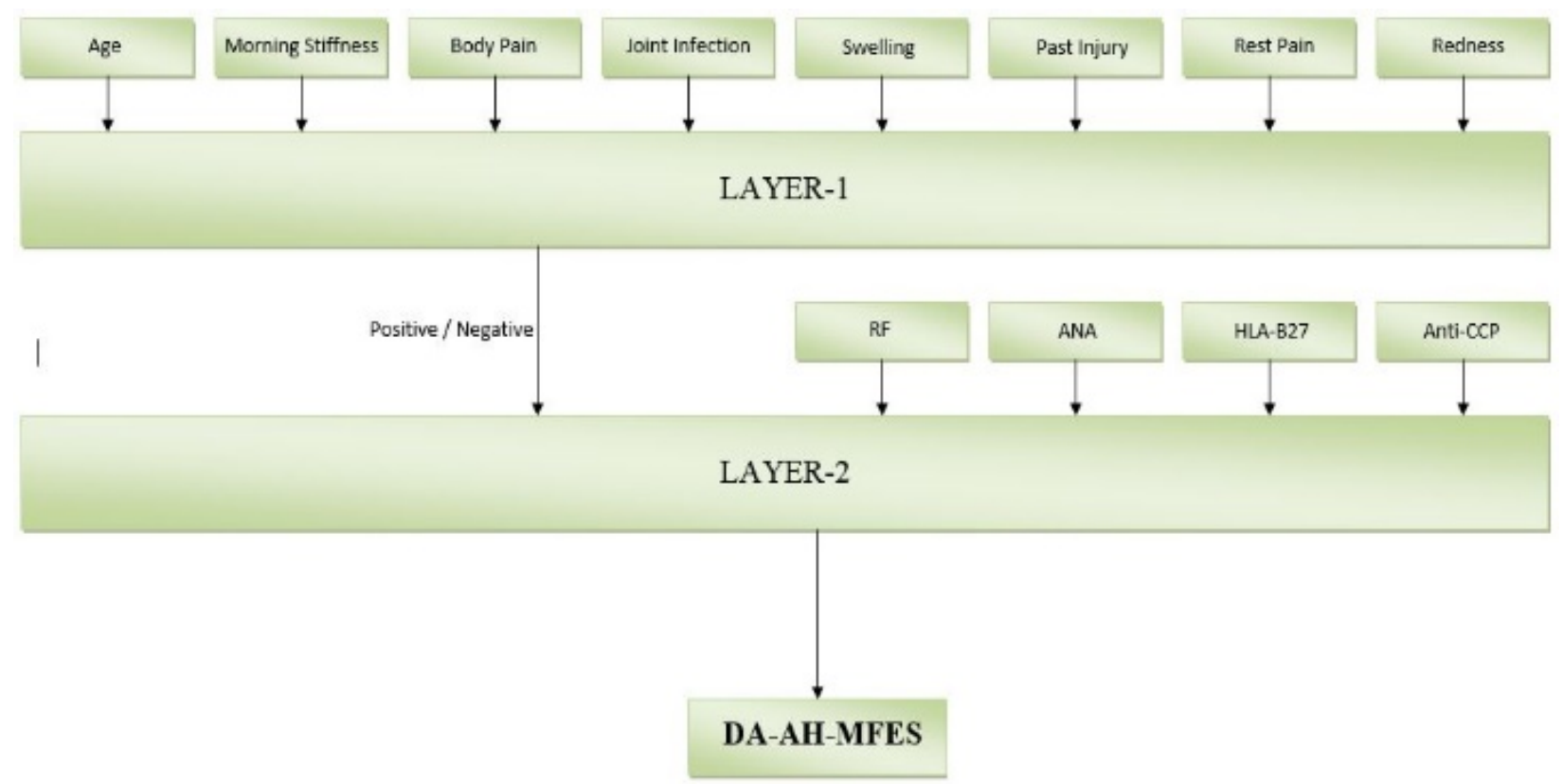

Figure 2. Proposed DA-AH-MFES Expert System 


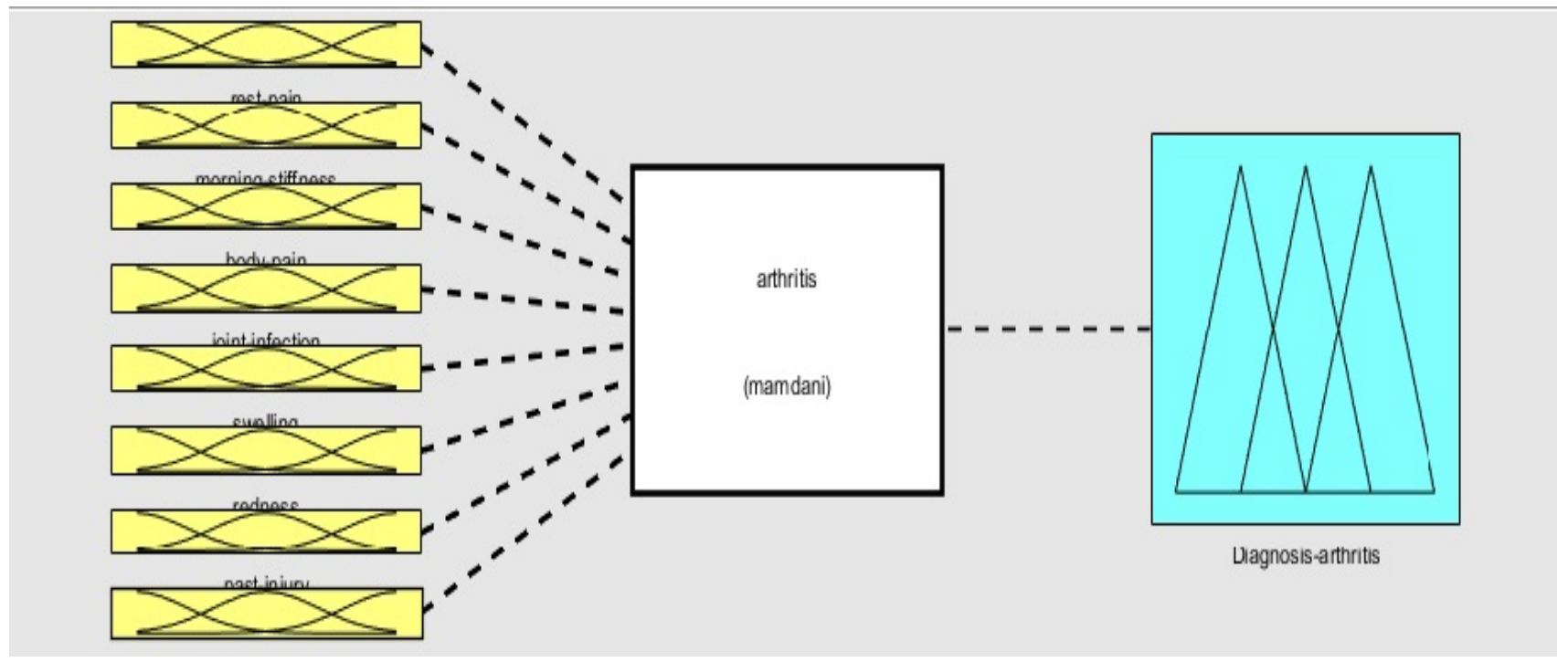

Figure 3. Layer-1 of Proposed DA-AH-MFES Expert System using MATLAB R2019a tool

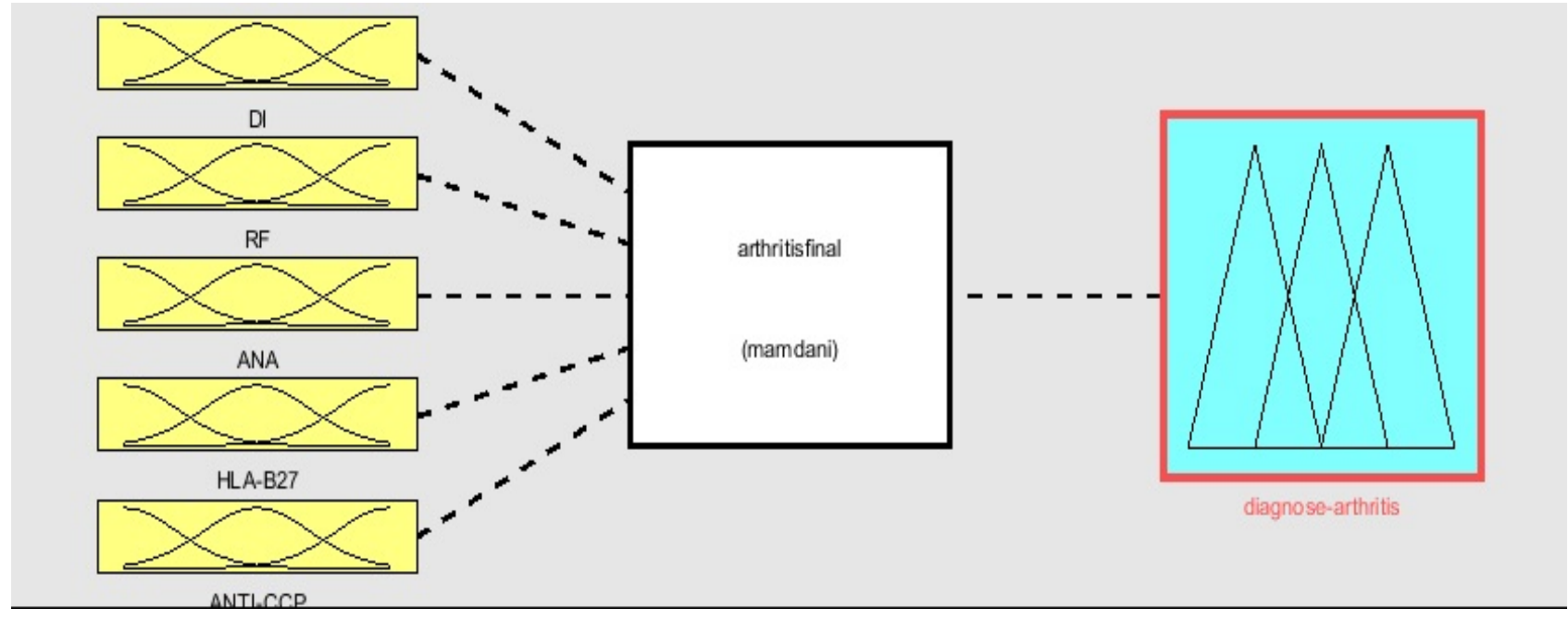

Figure 4. Layer-2 of Proposed DA-AH-MFES Expert System using MATLAB R2019a tool

The values of these parameters are also used to build up a lookup table given in Table-1 to evaluate the type of infection. The proposed automated Diagnosis Arthritis using mamdani inference based expert system can be expressed in mathematically regarding t-norm as

Proposed DA-AH-MFES for Layer-1 can be written mathematically as

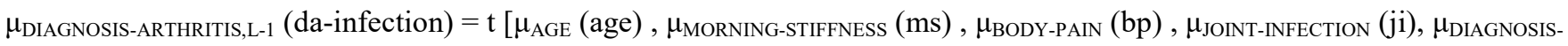
ARTHRITIS,L-1 $\left(\right.$ da-infection) $=\mathrm{t}\left[\mu_{\text {AGE }}(\right.$ age $), \mu_{\text {MORNING-STIFFNESS }}(\mathrm{ms}), \mu_{\text {BODY-PAIN }}(\mathrm{bp}), \mu_{\text {JOINT-INFECTION }}(\mathrm{ji}), \mu_{\text {DIAGNOSII- }}$ ARTHRITIS,LA-1 $\left(\right.$ da-infection) $=\min \left[\mu_{\text {AGE }}(\right.$ age $), \mu_{\text {MORNING-STIFFNESS }}(\mathrm{ms}), \mu_{\text {BODY-PAIN }}(\mathrm{bp}), \mu_{\text {JOINT-INFECTION }}(\mathrm{ji}), \mu_{\text {SWELLING }}(\mathrm{sw})$, $\left.\mu_{\text {PAST-INUJURY }}(\mathrm{pi}), \mu_{\text {REST-PAin }}(\mathrm{rp}), \mu_{\text {REDNESS }}(\mathrm{rn})\right]$

$\&$ Proposed DA-AH-MFES for Layer-2 can be written mathematically as 


$$
\begin{gathered}
\mu_{\text {DIAGNOSIS-ARTHRITIS,L-2 }}(\mathrm{da})=\mathrm{t}\left[\mu_{\mathrm{DI}}(\mathrm{di}), \mu_{\mathrm{RF}}(\mathrm{rf}), \mu_{\mathrm{ANA}}(\mathrm{ana}), \mu_{\mathrm{HLA}-\mathrm{B} 27}(\mathrm{hla}), \mu_{\mathrm{ANTI}-\mathrm{CCP}}(\mathrm{ac})\right] \\
\mu_{\text {DIAGNOSIS-ARTHRITIS,L-2 }}(\mathrm{da})=\min \left[\mu_{\mathrm{DI}}(\mathrm{di}), \mu_{\mathrm{RF}}(\mathrm{rf}), \mu_{\mathrm{ANA}}(\mathrm{ana}), \mu_{\mathrm{HLA}-\mathrm{B} 27}(\mathrm{hla}), \mu_{\mathrm{ANTI}-\mathrm{CCP}}(\mathrm{ac})\right]
\end{gathered}
$$

\subsection{Input Variables}

Proposed system Fuzzy input variables are numerical values that are used to diagnose arthritis. In this research, both layers used a total of twelve different kinds of input variables. Eight variables are used at layer-I and the remaining four variables are used at layers-II. The details of these input and output variables along with their ranges are shown in table 1 , table 2 and table 3.

Table 1. Layer-I input variables with medical ranges

\begin{tabular}{|c|c|c|c|}
\hline $\begin{array}{l}\mathrm{Sr} \\
\#\end{array}$ & $\begin{array}{c}\text { Input } \\
\text { Parameters }\end{array}$ & $\begin{array}{l}\text { Medical } \\
\text { Ranges }\end{array}$ & $\begin{array}{c}\text { Semantic } \\
\text { Sign }\end{array}$ \\
\hline \multirow[t]{3}{*}{1} & \multirow[t]{3}{*}{ AGE } & $\mathrm{LT}<18$ & Child \\
\hline & & B/W $15-40$ & Young \\
\hline & & $\mathrm{GT}>37$ & Old \\
\hline \multirow[t]{3}{*}{2} & \multirow{3}{*}{$\begin{array}{l}\text { MORNING } \\
\text { STIFFNESS }\end{array}$} & $\mathrm{LT}<0.2$ & No Pain \\
\hline & & $\begin{array}{c}\text { B/W } 0.1- \\
0.5\end{array}$ & Minimum \\
\hline & & GT $>0.4$ & Maximum \\
\hline \multirow[t]{3}{*}{3} & \multirow[t]{3}{*}{ BODY PAIN } & $\mathrm{LT}<17$ & No Pain \\
\hline & & B/W $10-43$ & Minimum \\
\hline & & $\mathrm{GT}>35$ & Maximum \\
\hline \multirow[t]{3}{*}{4} & \multirow{3}{*}{$\begin{array}{c}\text { JOINT } \\
\text { INFECTION }\end{array}$} & $\mathrm{LT}<7$ & No \\
\hline & & B/W 4-45 & Minimum \\
\hline & & $\mathrm{GT}>42$ & Maximum \\
\hline \multirow[t]{3}{*}{5} & \multirow[t]{3}{*}{ SWELLING } & $\mathrm{LT}<13$ & No \\
\hline & & B/W $8-45$ & Minimum \\
\hline & & $\mathrm{GT}>40$ & Maximum \\
\hline \multirow[t]{3}{*}{6} & \multirow[t]{3}{*}{ REDNESS } & $\mathrm{LT}<13$ & No \\
\hline & & B/W $8-45$ & Low \\
\hline & & $\mathrm{GT}>40$ & Maximum \\
\hline \multirow[t]{3}{*}{7} & \multirow[t]{3}{*}{ PAST INJURY } & $\mathrm{LT}<15$ & No \\
\hline & & B/W $7-42$ & Minimum \\
\hline & & GT > 35 & Maximum \\
\hline \multirow[t]{3}{*}{8} & \multirow[t]{3}{*}{ REST PAIN } & $\mathrm{LT}<0.20$ & No Pain \\
\hline & & $\begin{array}{c}\text { B/W } 0.1- \\
3.5\end{array}$ & Minimum \\
\hline & & GT > 3.4 & Maximum \\
\hline
\end{tabular}
of proposed DA-AH-MFES expert system

Table 2. Layer-II input variables with medical ranges

\begin{tabular}{|c|c|c|c|}
\hline $\begin{array}{l}\mathrm{Sr} \\
\#\end{array}$ & $\begin{array}{c}\text { Input } \\
\text { Parameters }\end{array}$ & Ranges & Semantic Sign \\
\hline \multirow[t]{3}{*}{1} & \multirow{3}{*}{$\frac{\text { Rheumatoid }}{\frac{\text { Factor }}{\text { (RF) }}}$} & $\mathrm{LT}<15$ & No \\
\hline & & B/W 7-42 & Minimum \\
\hline & & GT $>35$ & Maximum \\
\hline \multirow[t]{2}{*}{2} & \multirow{2}{*}{$\begin{array}{c}\text { Antinuclear } \\
\text { antibody } \\
\text { (ANA) }\end{array}$} & $L T<0.9$ & Negative \\
\hline & & $\mathrm{GT}>0.5$ & Positive \\
\hline \multirow[t]{2}{*}{3} & \multirow[t]{2}{*}{ HLA-B27 } & $\mathrm{LT}<0.9$ & Negative \\
\hline & & $\mathrm{GT}>0.5$ & Positive \\
\hline \multirow[t]{3}{*}{4} & \multirow[t]{3}{*}{ ANTI-CCP } & $\mathrm{LT}<15$ & No \\
\hline & & B/W 7-50 & Minimum \\
\hline & & $\mathrm{GT}>40$ & Maximum \\
\hline
\end{tabular}
of proposed DA-AH-MFES expert system

\subsection{Output Variables}

In this research, the multilayered mechanism is proposed to diagnose the Arthritis. If the layer-I output is positive then layer-II is activated. Output variables for both layers are shown in table 3 .

Table 3. Layer-I \& Layer-II output variables of proposed DA-AH-MFES expert system

\begin{tabular}{|c|c|c|c|}
\hline Sr \# & Layers & $\begin{array}{c}\text { Output } \\
\text { Variables }\end{array}$ & $\begin{array}{c}\text { Semantic } \\
\text { Sign }\end{array}$ \\
\hline 1 & Layer-I & $\begin{array}{c}\text { Diagnose } \\
\text { infection }\end{array}$ & Negative \\
\cline { 3 - 4 } & & PA-AH- & Positive \\
\cline { 4 - 4 } & Layer-II & MFES & $\begin{array}{c}\text { Acute } \\
\text { Mrthris }\end{array}$ \\
\cline { 4 - 4 } & & & Arthritis \\
\cline { 4 - 4 } & & & $\begin{array}{c}\text { Chronic } \\
\text { Arthritis }\end{array}$ \\
\hline
\end{tabular}

\subsection{Membership Functions}

Membership functions of the proposed automated DAAH-MFES Adroit System give the curve value except for truth values and also dispense a mathematical form of fuzzy logic that propose numerical values of both input and output variables. The membership function of this proposed automated DA-AH-MFES adroit system is shown in table 4 , table 5 and table 6 . These membership functions are established with the help of Cavan General Hospital Lisdaran, Cavan, Ireland and Jinnah Hospital Lahore, Pakistan medical experts. 
Table 4. Mathematical \& Graphical MF of Layer-1 Mamdani Fuzzy Inference System Input variables

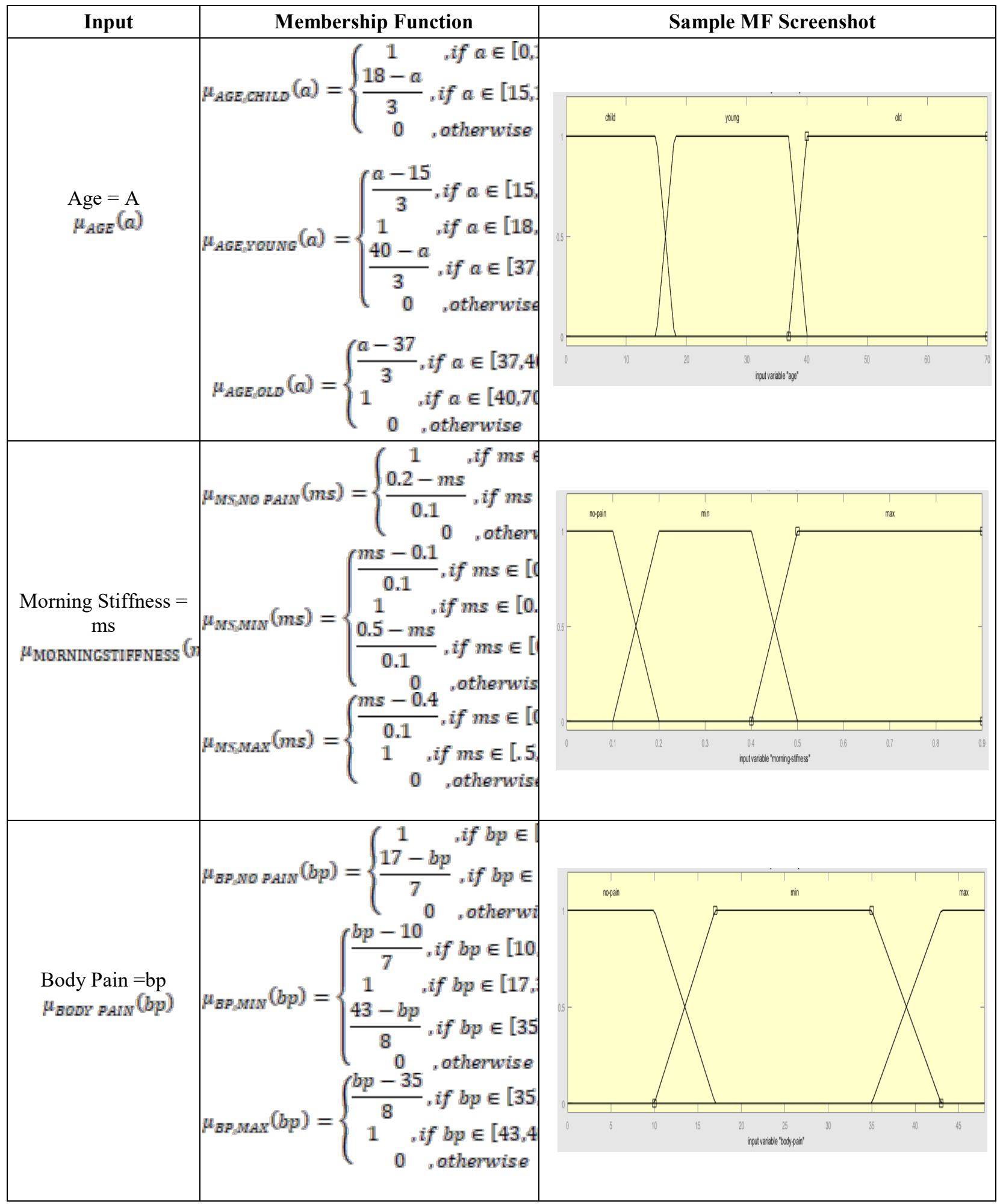




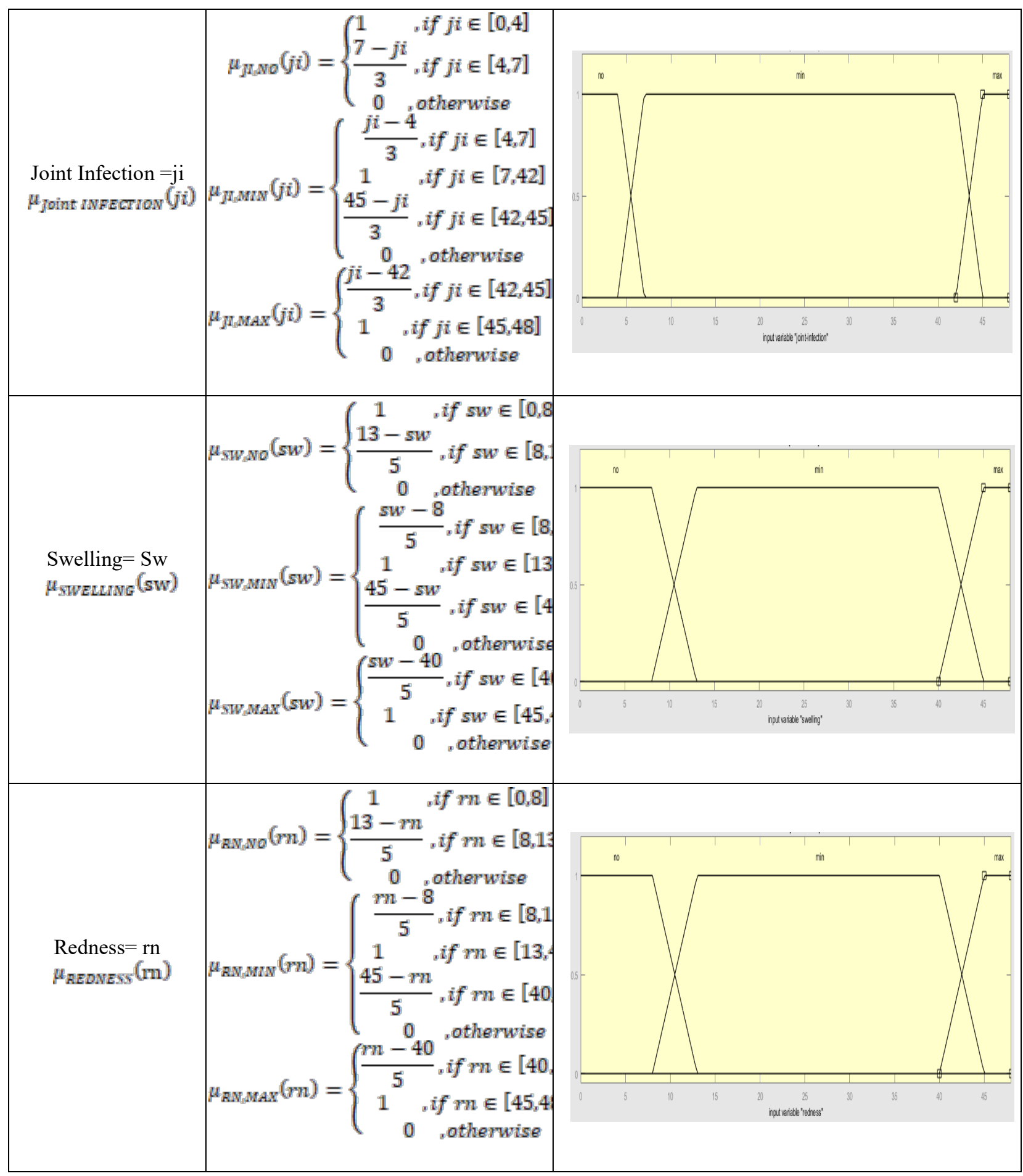




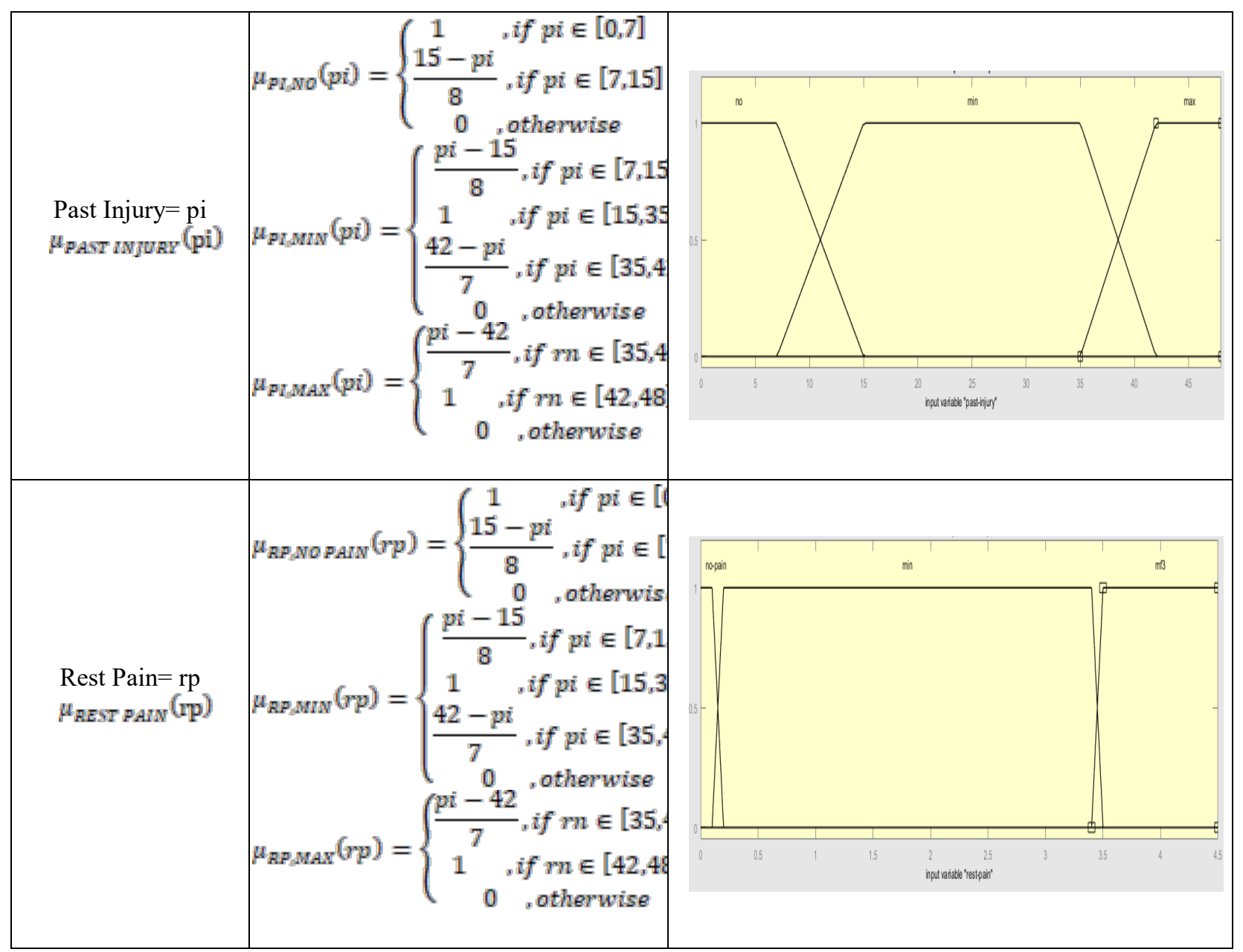

Table 5. Mathematical \& Graphical MF of Layer-2 Mamdani Fuzzy Inference System Input variables

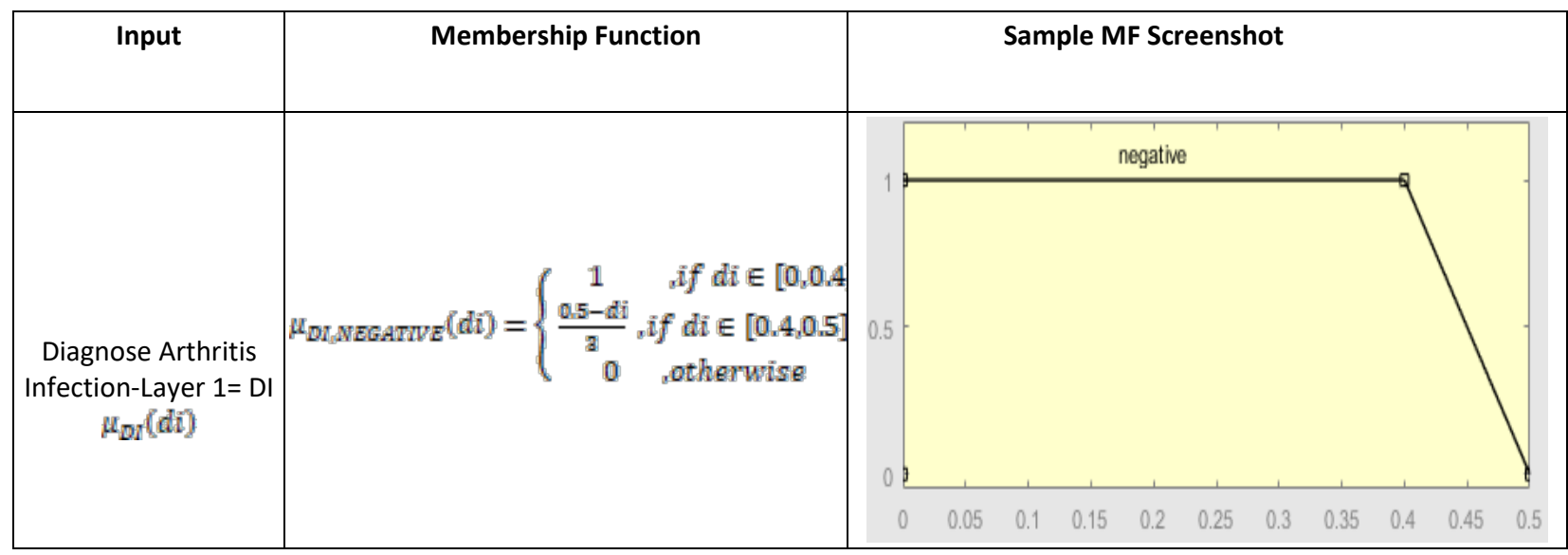




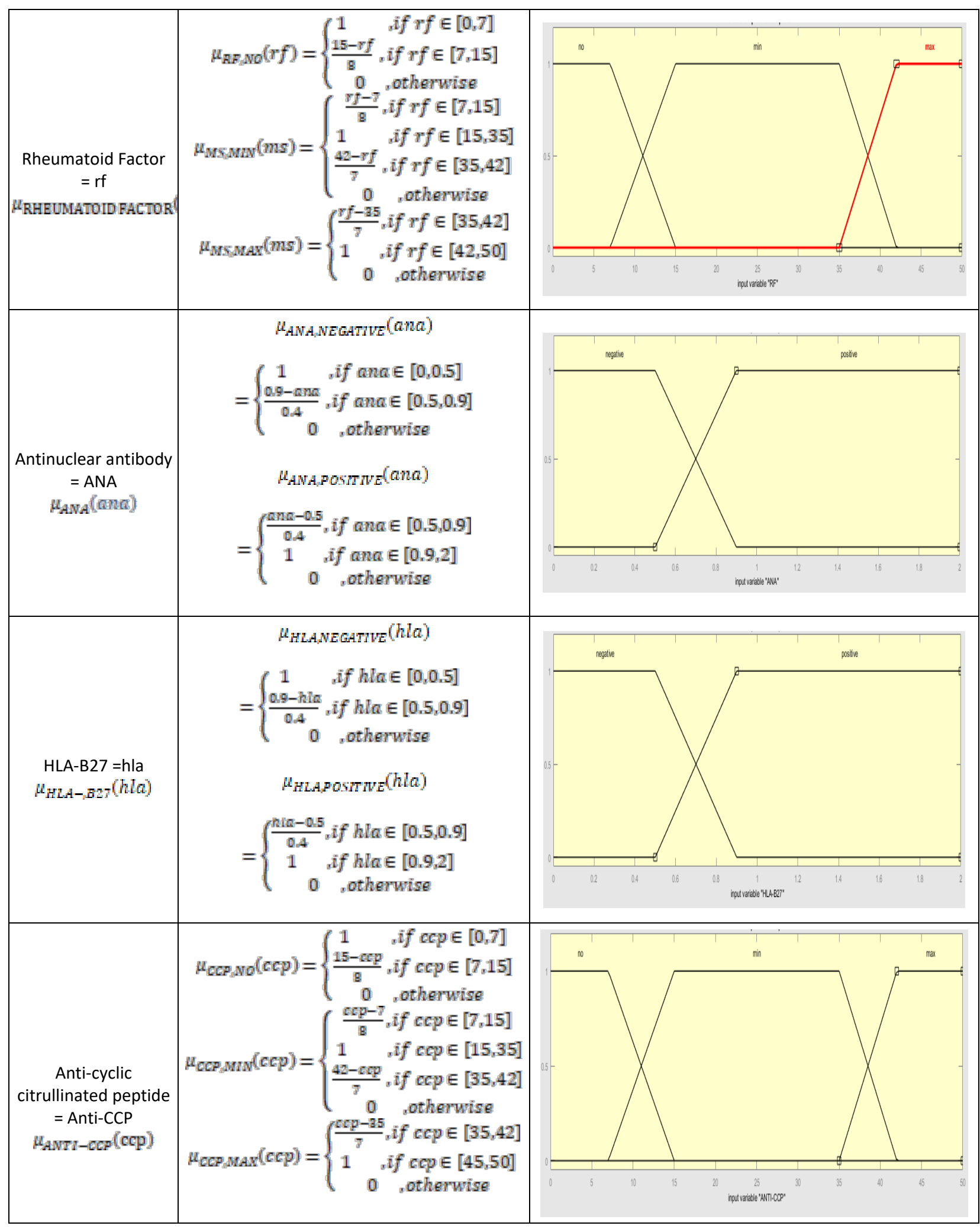

Table 6. Mathematical \& Graphical MF of Layer-1 \& Layer-2 Mamdani Fuzzy Inference System Output variables 


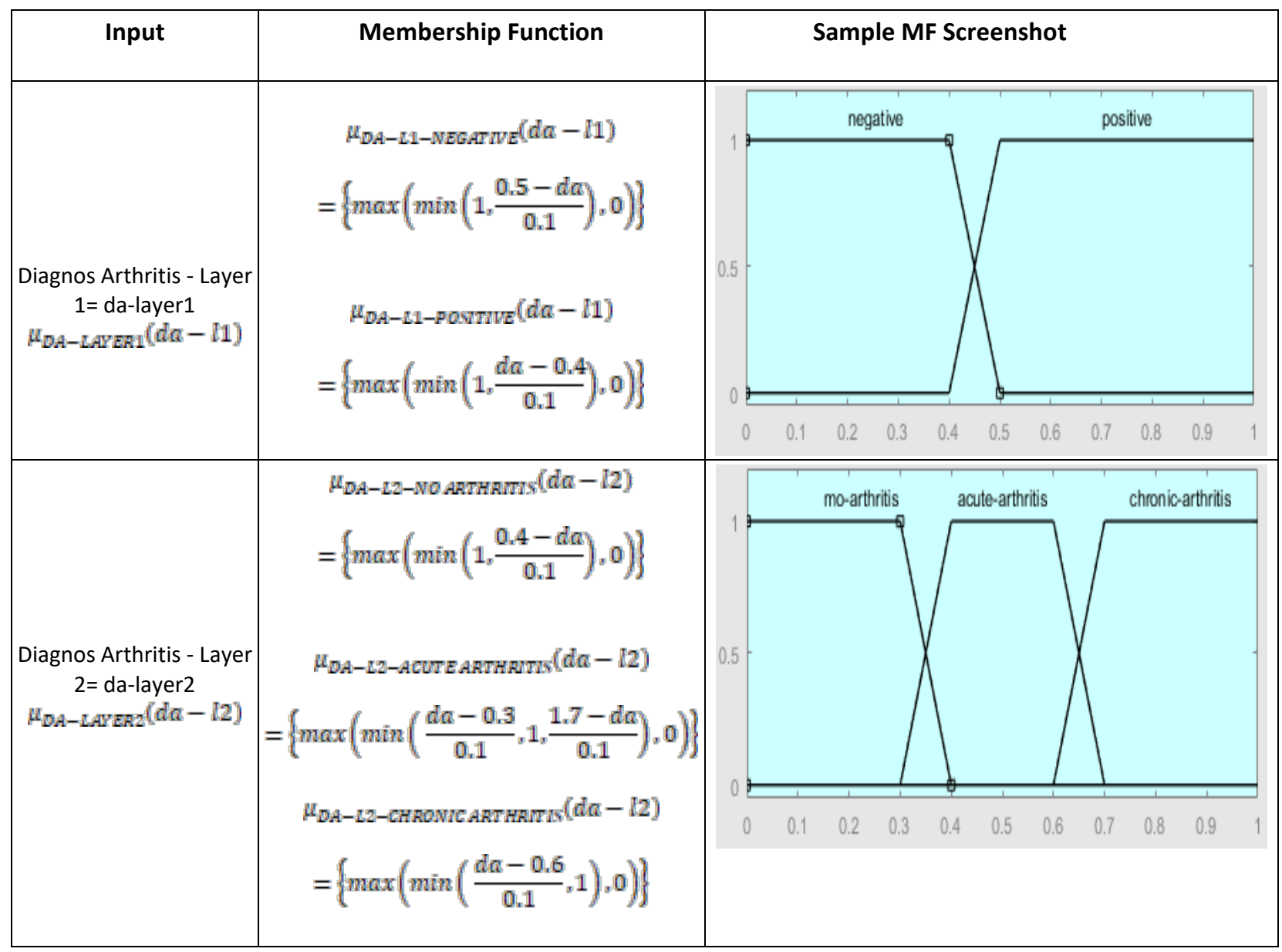

\subsection{Rules-Base Lookup Table}

For the proposed DA-AH-MFES rules table, which usually relies on the expert system comprises of 6561 input and output rules for layer 1 and 36 input and output rules for layer 2. A few of these input and output rules for layer 1 and layer 2 are presented in table 7 and table 8 respectively. The rule table is generally generated to the assistance of medical experts from the Orthopedic department of Cavan General Hospital Lisdaran, Cavan, Ireland and Jinnah Hospital Lahore, Pakistan.

Table 7. Lookup table of Layer -I for DA-AH-MFES Expert System

\begin{tabular}{|l|l|l|l|l|l|l|l|l|l|}
\hline Rules & Age & $\begin{array}{l}\text { Mornin } \\
\mathbf{g} \\
\text { Stiffnes } \\
\mathbf{s}\end{array}$ & $\begin{array}{l}\text { Body } \\
\text { Pain }\end{array}$ & $\begin{array}{l}\text { Joint } \\
\text { Infectio } \\
\mathbf{n}\end{array}$ & Swelling & $\begin{array}{l}\text { Past } \\
\text { Injury }\end{array}$ & $\begin{array}{l}\text { Rest } \\
\text { Pain }\end{array}$ & $\begin{array}{l}\text { Rednes } \\
\text { s }\end{array}$ & Results \\
\hline 1 & Child & No & No & No & No & No & No & No \\
\hline 2 & Child & Min & Min & No & Min & Min & No & No \\
\hline 3 & Young & Min & Min & No & No & No & No & Max \\
\hline 4 & Young & Max & No & No & Min & Min & No & No \\
\hline 5 & Old & No & Min & Min & No & No & Min & No \\
\hline 6 & Old & Max & No & No & Min & No & Min & No \\
\hline 7 & Child & Min & No & No & Min & Min & Min & Min \\
\hline
\end{tabular}




\begin{tabular}{|l|l|l|l|l|l|l|l|l|l|}
\hline Rules & Age & $\begin{array}{l}\text { Mornin } \\
\mathbf{g} \\
\text { Stiffnes } \\
\mathbf{S}\end{array}$ & $\begin{array}{l}\text { Body } \\
\text { Pain }\end{array}$ & $\begin{array}{l}\text { Joint } \\
\text { Infectio } \\
\mathbf{n}\end{array}$ & Swelling & $\begin{array}{l}\text { Past } \\
\text { Injury }\end{array}$ & $\begin{array}{l}\text { Rest } \\
\text { Pain }\end{array}$ & $\begin{array}{l}\text { Rednes } \\
\text { s }\end{array}$ & Results \\
\hline 8 & Young & No & Max & Max & Max & Min & Min & Max & Max \\
\hline 9 & Old & Min & Max & Max & Max & Min & Min & Positive \\
\hline 10 & Old & Max & Min & Max & Min & Max & Max & Min \\
\hline 11 & Young & Max & Max & Max & Min & Min & Max & Min \\
\hline
\end{tabular}

Table 8. Lookup Table of Layer -II for DA-AH-MFES Expert System

\begin{tabular}{|c|c|c|c|c|c|c|}
\hline Rules & DI & RF & ANA & HLA-B27 & ANTI-CCP & Output \\
\hline 1 & Positive & No & Negative & Negative & No & \multirow{4}{*}{ No Arthritis } \\
\hline 2 & Positive & Minimum & Negative & Negative & No & \\
\hline 3 & Positive & No & Positive & Negative & No & \\
\hline 4 & Positive & No & Negative & Positive & No & \\
\hline 5 & Positive & No & Positive & Positive & Minimum & \multirow{4}{*}{$\begin{array}{c}\text { Acute } \\
\text { Arthritis }\end{array}$} \\
\hline 6 & Positive & Minimum & Positve & Negative & Minimum & \\
\hline 7 & Positive & Maximum & Positive & Negative & No & \\
\hline 8 & Positive & Minimum & Negative & Positive & Minimum & \\
\hline 9 & Positive & Minimum & Negative & Negative & Maximum & \multirow{4}{*}{$\begin{array}{l}\text { Chronic } \\
\text { Arthritis }\end{array}$} \\
\hline 10 & Positive & Maximum & Negative & Positive & Minimum & \\
\hline 11 & Negative & Maximum & Positive & Positive & Minimum & \\
\hline 12 & Negative & Maximum & Positive & Positive & Maximum & \\
\hline
\end{tabular}

\section{Rule-Based}

Rules are fundamental for input and output variables for both layers. The accomplishment of an Expert system constructs based on input an output rules. All rules for the proposed DA-AH-MFES appeared in figure 5.

\section{Inference Engine}

Inference Engine is the essential constituent of any decision based self-ruling framework. In this exposition of DA-AH-MFES, the Inference model is used in Layer I and

II. 


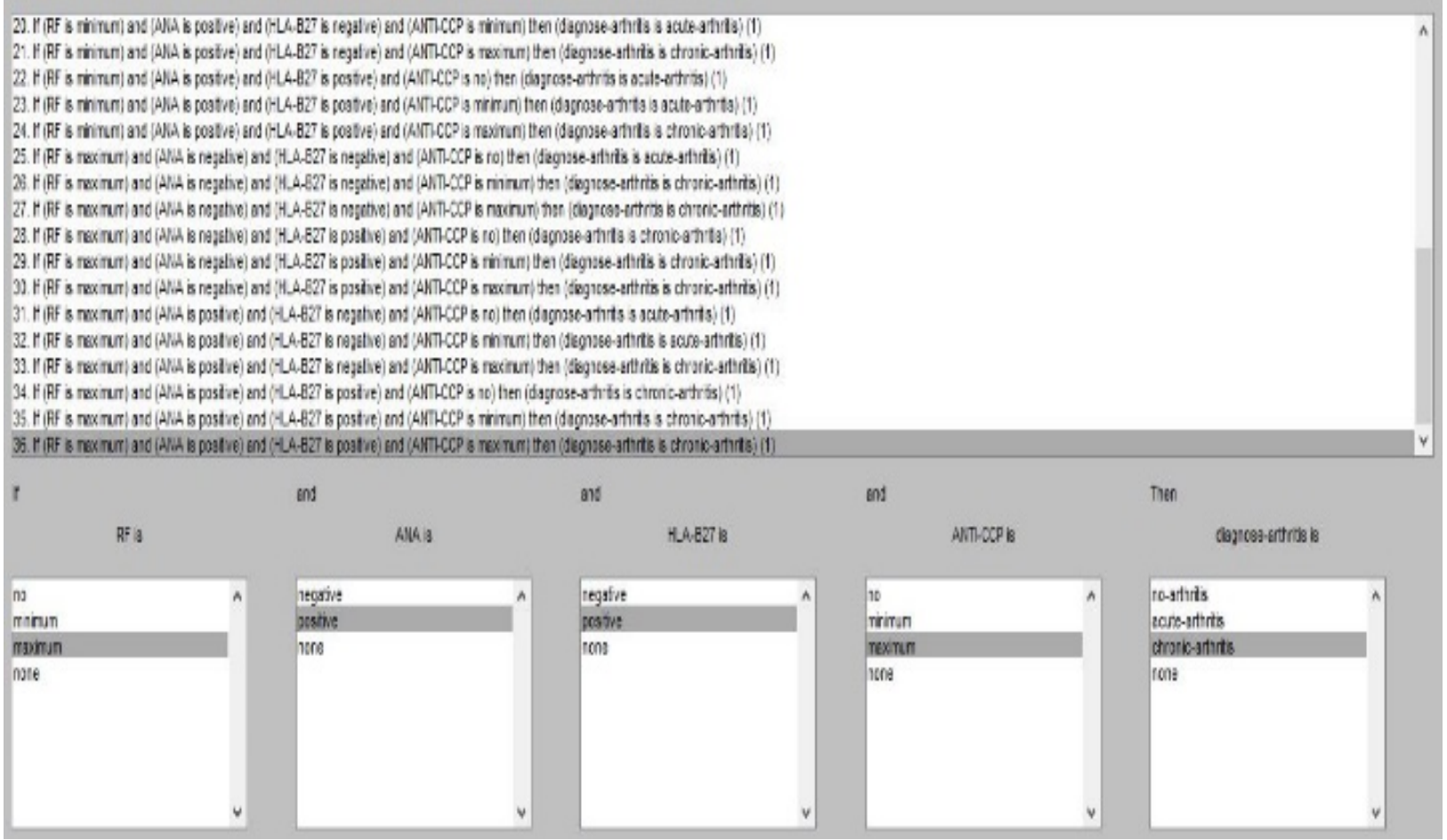

Figure 5. Rules-based system for DA-AH-MFES Adroit System

\section{De-Fuzzifier}

De-Fuzzifier is one of the fundamental sections of any decision based self-governing framework. There are different sorts of defuzzifier. In this examination centroid type of De-fuzzifier is used. Figure 6 of all sections $6 a-6 d$, demonstrates the De-fuzzifier graphical representation of both layers administers in DA-AH-MFES.

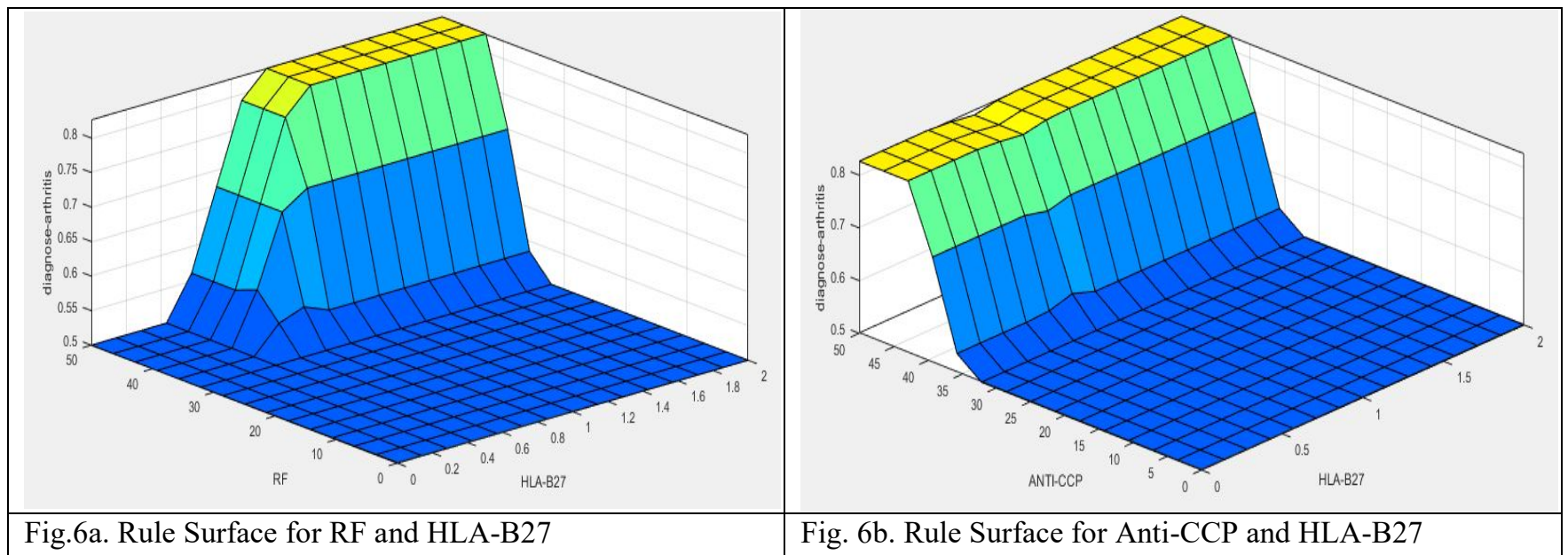




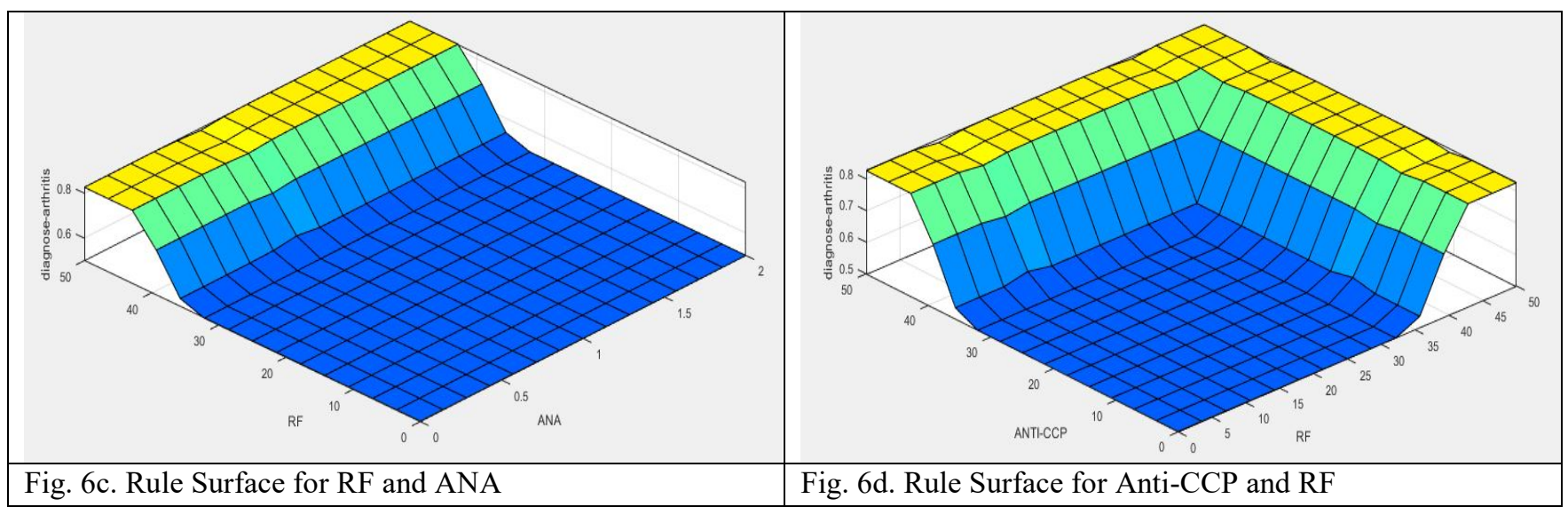

Figure 6. De-Fuzzifier graphical illustrations of Proposed DA-AH-MFES Expert System

In Figure.6a blue color reperent the no arthritis, green color represent the acute arthritis and yellow color represent the chronic arthritis. The Arthritis (regarding Probability) based on Rheumatoid Factor and HLA-B27. Different colors in the Surface region present the stages of Arthritis. It is also observed that if Rheumatoid Factor is no (with the range between 0-15) and HLA-B27 less than 0.9 then the probability of arthritis is 0 that it may be any other types of arthritis. It is also observed that if the costs of Rheumatoid Factor are more the 35 its mean maximum and amounts of HLA-B27 are less the 0.9, the value of Arthritis is $80 \%$ that means it is no \& chronic arthritis.

Correspondingly, remaining figures $6 \mathrm{~b}-6 \mathrm{~d}$ present workmanship results by winning distinctive info parameter values. The surface district speaks to likelihood values by two information factors from given twelve input variables. The arthritis results are the blend of in any event three information factors.

\section{Simulation and Results}

MATLAB R2019a [33] tool is used for representing, simulated, algorithm development, prototyping, and many other fields. This tool is efficient for software designing, data analysis, outset, and calculations. For the simulation of results, twelve inputs on both layers one output of diagnosing arthritis are used which are shown in figures 7 , 8 and 9.
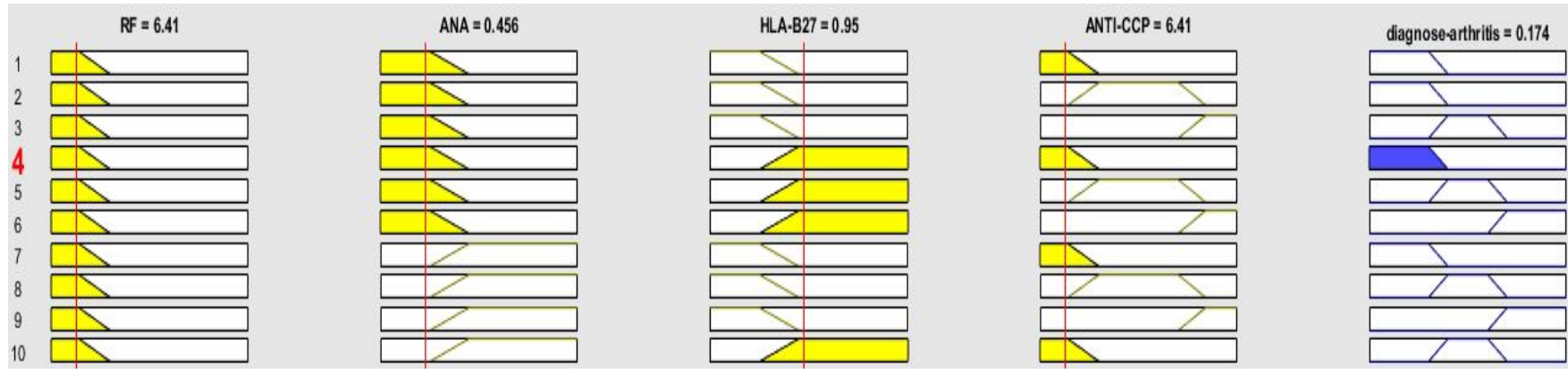

Figure 7. Lookup diagram of Proposed DA-AH-MFES Expert System for No- Arthrists
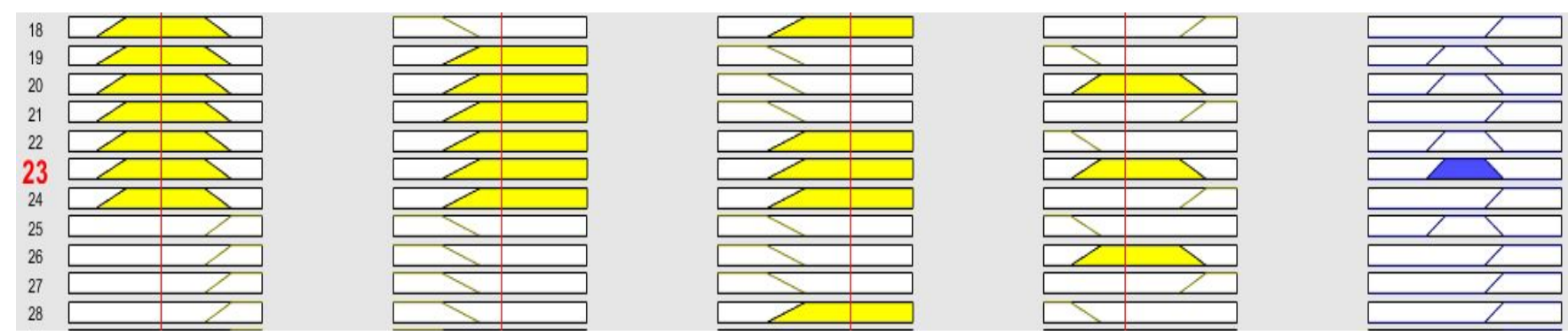
Figure 8. Lookup diagram of Proposed DA-AH-MFES Expert System for Acute Arthritis
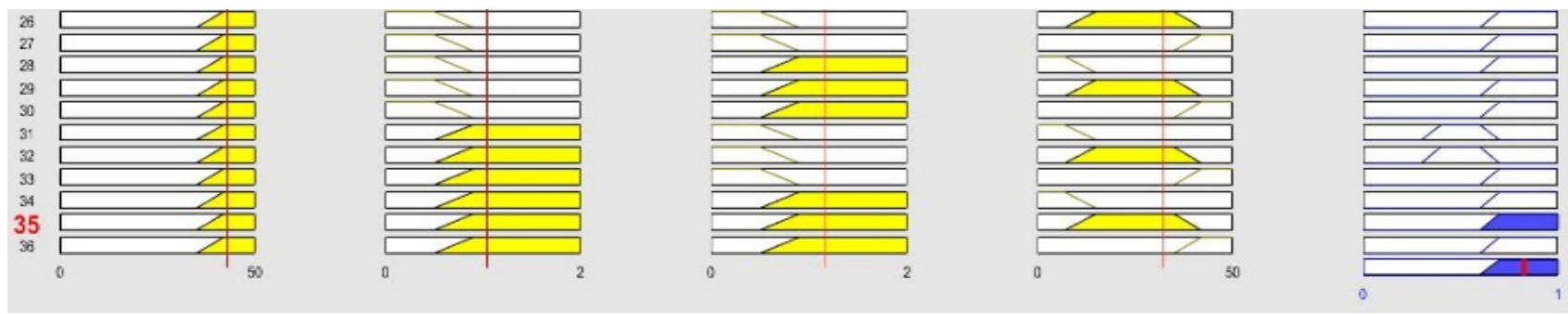

Figure 9. Lookup diagram of Proposed DA-AH-MFES Expert System for Chronic Arthritis

Figure 7 shows, If $\mu_{\text {RHEUMATOID-FACTOR }}$ (rf) is considered no, $\mu_{\mathrm{ANA}}(\mathrm{ana})$ is negative, $\mu_{\mathrm{HLA}-\mathrm{B} 27}$ (hla) is positive, $\mu_{\mathrm{ANTI}}$ CCP (ccp) is no, then Outcome for $\mu_{\text {DA-LAYER2 }}(\mathrm{da}-12)$ is No arthritis.

Figure 8 shows, If $\mu_{\text {RHEUMATOID-FACTOR }}$ (rf) is considered minimum, $\mu_{\mathrm{ANA}}$ (ana) is positive, $\mu_{\mathrm{HLA}-\mathrm{B} 27}$ (hla) is positive, $\mu_{\text {ANTI-CCP }}(\mathrm{ccp})$ is minimum, then Outcome for $\mu_{\text {DA-LAYER2 }}$ (da-12) is acute arthritis.

Figure 9 shows, If $\mu_{\text {RHEUMATOID-FACTOR }}$ (rf) is considered maximum, $\mu_{\mathrm{ANA}}$ (ana) is positive, $\mu_{\mathrm{HLA}-\mathrm{B} 27}$ (hla) is positive, $\mu_{\text {ANTI-CCP }}(\mathrm{ccp})$ is maximum, then Outcome for $\mu_{\text {DA-LAYER2 }}(\mathrm{da}-12)$ is chronic arthritis.

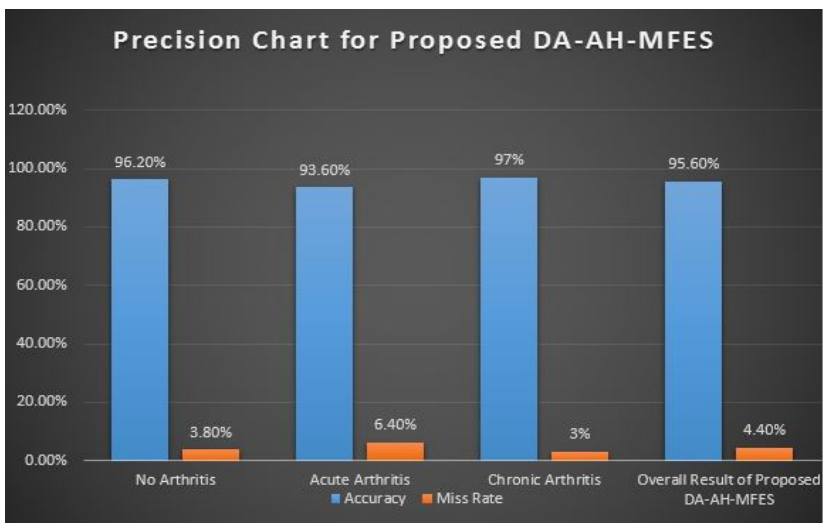

\section{Figure 10. Precision Chart of Proposed DA-AH-MFES Expert System}

The viability of the proposed method has sporadically kept an eye on many records. The Proposed DA-AHMFES expert system gives definite outcomes for all stages, and just at acute arthritis, it might achieve some slight errors. Figure 10 speaks to the precision rate of DAAH-MFES for the detection of arthritis. The proposed framework demonstrates the exactness rate for no arthritis is 96.20 percent, for acute arthritis is 93.60 percent and for chronic arthritis is 97 percent. The overall precision of the proposed DA-AH-MFES is 95.60 percent and the miss rate of the proposed DA-AH-MFES turns out to be 4.40 percent.

\section{Conclusion}

The basic point of convergence of our examination is to devise an expert system to examine arthritis by reports retrieved from the Cavan General Hospital Lisdaran, Cavan, Ireland and Jinnah Hospital Lahore, Pakistan. This expert system is principal and simpler to use for both Medical specialists and non-specialists. This research engages orthopedic experts, surgeons and lab technicians for the judgment of the propose DA-AH-MFES expert system performance. Research obtained through the fuzzy logic model is critically analyzed in the supervision of orthopedic experts, surgeons and lab technicians. They conclude that this fuzzy logic model is to provide reliable results in the field of arthritis disease. The particular goal of this study is to analyze the various dimensions of arthritis. The overall accuracy of this proposed DA-AHMFES is $95.6 \%$. In the future, the productivity of the presented framework can be enhanced utilizing different methods including Computational Intelligence as Deep Learning, Neuro-fuzzy, and Neural networks.

\section{References}

[1] Krock, E., Jurczak, A., \& Svensson, C. I. (2018). Pain pathogenesis in rheumatoid arthritis-what have we learned from animal models?. Pain, 159, S98-S109.

[2] Giles, J. T., Danielides, S., Szklo, M., Post, W. S., Blumenthal, R. S., Petri, M., ... \& Bathon, J. M. (2009). Insulin Resistance in Rheumatoid Arthritis. Imaging, 67(3), pp626-636.

[3] Ruiz, D. G., Azevedo, M. N. L. D., \& Lupi, O. (2012). HLA-B27 frequency in a group of patients with psoriatic arthritis. Anais brasileiros de dermatologia, 87(6), 847850.

[4] Krastanova, M. S., \& Vacheva, D. E. (2015). COMPLEX FUNCTIONAL ASSESSMENT OF THE HIP JOINT. 
Journal of IMAB-Annual Proceeding Scientific Papers, 21(3), 883-886.

[5] Gonzalez, S., Garcia-Fernandez, S., Martinez-Borra, J., Blanco-Gelaz, M. A., Rodrigo, L., del Río, J. S., ... \& López-Larrea, C. (2002). High variability of HLA-B27 alleles in ankylosing spondylitis and related spondyloarthropathies in the population of northern Spain. Human immunology, 63(8), 673-676.

[6] Majithia, V., \& Geraci, S.A. (2007). Rheumatoid arthritis: Diagnosis and management. The American Journal of Medicine, 120(11), 936-939.

[7] Khan, M. A., Abbas, S., Hasan, Z., \& Fatima, A. Intelligent Transportation System (ITS) for Smart-Cities using Mamdani Fuzzy Inference System.

[8] Ahmad, G., Khan, M. A., Abbas, S., Athar, A., Khan, B. S., \& Aslam, M. S. (2019). Automated Diagnosis of Hepatitis B Using Multilayer Mamdani Fuzzy Inference System. Journal of healthcare engineering, 2019.

[9] Wu, R., Peters, W., \& Morgan, M. W. (2002). The next generation of clinical decision support: linking evidence to best practice. Journal of healthcare information management: JHIM, 16(4), 50-55.

[10] Vine, M. "Understanding Arthritics and its care", Chesterfield, UK, Arthritics Medical Press, 2016.

[11] Bhatla, N., \& Jyoti, K. (2012). A Novel Approach for heart disease diagnosis using Data Mining and Fuzzy logic. International Journal of Computer Applications, 54(17).

[12] Singh, S., Kumar, A., Panneerselvam, K., \&Vennila, J. J. (2012). Diagnosis of arthritis through a fuzzy inference system. Journal of Medical Systems, 36(3), 1459-1468

[13] Asadullah, M., Khan, M. A., Abbas, S., Athar, A., Raza, S. S., \& Ahmad, G. (2018). Blind channel and data estimation using fuzzy logic-empowered opposite learning-based mutant particle swarm optimization. Computational intelligence and neuroscience, 2018.

[14] ESPINOZA, L. R., TOLOZA, S. M., VALLE-ONATE, R. A. F. A. E. L., \& MEASE, P. J. (2012). Global partnering opportunities and challenges of psoriasis and psoriatic arthritis in Latin America: a report from the GRAPPA 2010 annual meeting.

[15] Anderson, J., Caplan, L., Yazdany, J., Robbins, M. L., Neogi, T., Michaud, K. \&Kazi, S. (2012). Rheumatoid arthritis disease activity measures: American College of Rheumatology recommendations for use in clinical practice. Arthritis care \& research, 64(5), 640-647.

[16] McInnes, I. B., \&Schett, G. (2011). The pathogenesis of rheumatoid arthritis. New England Journal of Medicine, 365(23), 2205-2219.

[17] Berenbaum, F. (2013). Osteoarthritis is an inflammatory disease (osteoarthritis is not osteoarthrosis!). Osteoarthritis and cartilage, 21(1), 16-21.

[18] Smolen, J. S., Breedveld, F. C., Burmester, G. R., Bykerk, V., Dougados, M., Emery, P., \&Scholte-Voshaar, M. (2016). Treating rheumatoid arthritis to target: 2014 update of the recommendations of an international task force. Annals of the rheumatic diseases, 75(1), 3-15.

[19] Imran, M. Y., Khan, E. A. S., Ahmad, N. M., Raja, S. F., Saeed, M. A., \&Haider, I. I. (2015). Depression in Rheumatoid Arthritis and its relation to disease activity. Pakistan journal of medical sciences, 31(2), 393.

[20] Watt, I. (1997). Basic differential diagnosis of arthritis. European radiology, 7(3), 344-351.

[21] Singh, J. A., Saag, K. G., Bridges Jr, S. L., Akl, E. A., Bannuru, R. R., Sullivan, M. C \& Curtis, J. R. (2016). 2015 American College of Rheumatology guideline for the treatment of rheumatoid arthritis. Arthritis \& rheumatology, 68(1), 1-26.

[22] Hussain, S., Abbas, S., Sohail, T., Adnan Khan, M., \& Athar, A. Estimating virtual trust of cognitive agents using multi-layered socio-fuzzy inference system. Journal of Intelligent \& Fuzzy Systems, (Preprint), 1-16.

[23] Areej Fatima, Muhammad Adnan Khan, Sagheer Abbas, Muhammad Waqas, Leena Anum, and Muhammad Asif, Evaluation of Planet Factors of Smart City through Multilayer Fuzzy Logic (MFL). The ISC Int'l Journal of Information Security. 51-58, 2019.

[24] Ayesha Atta, Sagheer Abbas, M Adnan Khan, Gulzar Ahmed, and Umer Farooq. An adaptive approach: Smart traffic congestion control system. Journal of King Saud University-Computer and Information Sciences, 2018.

[25] Khan, M. A., Umair, M., Saleem, M. A., Ali, M. N., \& Abbas, S. (2019). CDE using improved opposite based swarm optimization for MIMO systems. Journal of Intelligent \& Fuzzy Systems, 37(1), 687-692.

[26] Khan, M. A., Umair, M., \& Choudhry, M. A. S. (2015). GA based adaptive receiver for MC-CDMA system. Turkish Journal of Electrical Engineering \& Computer Sciences, 23(Sup. 1), 2267-2277.

[27] Khan, M. A., Umair, M., \& Choudry, M. A. S. (2015, December). Island differential evolution based adaptive receiver for MC-CDMA system. In 2015 International Conference on Information and Communication Technologies (ICICT) (pp. 1-6). IEEE.

[28] Ali, M. N., Khan, M. A., Adeel, M., \& Amir, M. (2016). Genetic Algorithm based adaptive Receiver for MCCDMA system with variation in Mutation Operator. International Journal of Computer Science and Information Security, 14(9), 296.

[29] Umair, M., Khan, M. A., \& Choudry, M. A. S. (2015, December). Island genetic algorithm based MUD for MCCDMA system. In 2015 International Conference on Information and Communication Technologies (ICICT) (pp. 1-6). IEEE.

[30] Umair, M., Khan, M. A., \& Choudry, M. A. S. (2013, January). GA backing to STBC based MC-CDMA systems. In 2013 4th International Conference on Intelligent Systems, Modelling and Simulation (pp. 503506). IEEE.

[31] Kashif, I., Muhammad, A.K., Sagheer, A., Zahid, H., \& Areej, F (2018). Intelligent Transportation System (ITS) for Smart-cities using Mamdani Fuzzy Inference System, International Journal of Advanced Computer Science and Applications (IJACSA). ISSN: 2158-107X, Vol. 9, No. 2, (pp. 94-105), Digital Object Identifier (DOI): 10.14569/IJACSA.2018.090215.

[32] Wang, H., Zhang, Z., \& Taleb, T. (2018). Special issue on security and privacy of IoT. World Wide Web, 21(1), 1-6.

[33] MATLAB for Artificial Intelligence (www.mathworks.com)

[34] Liu, F., Zhou, X., Wang, Z., Cao, J., Wang, H., \& Zhang, Y. (2019). Unobtrusive Mattress-Based Identification of Hypertension by Integrating Classification and Association Rule Mining. Sensors, 19(7), 1489.

[35] Liu, F., Zhou, X., Cao, J., Wang, Z., Wang, H., \& Zhang, Y. (2019, May). A LSTM and CNN Based Assemble Neural Network Framework for Arrhythmias Classification. In ICASSP 2019-2019 IEEE International Conference on Acoustics, Speech and Signal Processing (ICASSP) (pp. 1303-1307). IEEE.

[36] Arrhythmias classification by integrating stacked bidirectional LSTM and two-dimensional CNN. Pacific- 
Asia Conference on Knowledge Discovery and Data Mining, 136-149, 2019.

[37] Dynamic optimisation based fuzzy association rule mining method. International Journal of Machine Learning and Cybernetics 10 (8), 2187-2198, 2019. 